\title{
Speeding up Vocabulary Acquisition through Action Research
}

\author{
Ameerchund (Ashraf) Maharaj \\ King Abdulaziz University, Jeddah, Saudi Arabia \\ E-mail: ashrafmaharaj@yahoo.com
}

Received: 29-12-2016

Published: 01-07-2017
Accepted: 25-03-2017

doi:10.7575/aiac.ijalel.v.6n.4p.245
Advance Access Published: April 2017

URL: http://dx.doi.org/10.7575/aiac.ijalel.v.6n.4p.245

\begin{abstract}
Gaining a wider vocabulary is fundamental to language learning. It follows then that the faster students engage and learn new words, the faster will be their proficiency with the target language. Multi-Dimensional Vocabulary Acquisition (or MDVA) means approaching new terms / concepts from a variety of perspectives so that the target word is thoroughly analysed, giving students access to all dimensions of the word. There are many dimensions or elements that will help elucidate and unlock meaning, but for the purposes of this chapter new words will be looked at in terms of their antonyms, synonyms and associated words, rhyming counterparts, idiomatic usage, gender considerations, diminutive implications, proverbial usage and likely confusion with other words. In this study the author employs an Action Research methodology where practical classroom exercises involving students' writing efforts pre- and post MDVA are closely examined. Using the familiar "spiral of cycles" approach, it becomes clear that "unpacking" the target word means that the meaning of many other words associated with the target word becomes explicit. A workshop with faculty is included as part of the practical application of MDVA.
\end{abstract}

Keywords: Multi-dimensional, target word, lexis, vocabulary acquisition

\section{Introduction}

One of the characteristics of EFL/ESL students is their restricted vocabulary. This is a constantly recurring feature of the author's work environment. As a teacher-facilitator, one realizes that this limitation in lexis has a knock on effect in the sense that it affects how much students understand when the teacher speaks, their ability to understand what they read or hear, their own ability to elaborate when they speak, the quality of their writing, etc. In other words, a restricted vocabulary means slow or possibly no development in the skills normally associated with English language learning.

This action research based article is addressed to both native and non-native teachers of English. It is an attempt to identify and expound on a novel approach to vocabulary acquisition, with resultant consequences for writing. An often neglected aspect of learning English as second language is vocabulary enrichment / extension. According to Gass and Selinker (200:372) “...there are numerous reasons for believing that lexis is important in second language acquisition. In fact, the lexicon may be the most important language component for learners." In cases where vocabulary is the focus, ESL learners are often taught new terms in a strictly one-dimensional manner, that is, they are exposed to just a single definition of key words. Students thus leave the classroom with a narrow understanding of words. Meaning is constrained thus giving students a restricted understanding of words and concepts. This is quite understandable given the fact that English is a second or foreign language and that students may not be expected to use the language very widely. However, in an era of increasing globalization where English usage in all fields of knowledge is hegemonic, expanding students' vocabulary repertoire becomes more and more paramount. Students need to understand that specific words have a multiplicity of meanings and are thus context-bound. As such, the meaning of the same word may be different depending on the context in which it is used. Consider, for example, the following exchange between two workers:

W1 : The boss is really proud of my late uncle Fred.

W2 : The boss must be crazy!

W1 : Why do you say that?

W2 : How can the boss be proud of a worker who is always late?

It is clear from the above that both speakers are using the word "late" in a different context. It is also obvious that W2 has one understanding of the word "late" i.e. the temporal sense of the word. His / Her teacher probably didn't explain the other meaning of "late" i.e. having passed on or being dead.

Other examples to consider would be the following:

1. The rich man was willing to $\underline{\text { lend }}$ money to anyone who wanted to $\underline{\text { borrow }}$.

2. Being a peasant isn't very pleasant!! 
3. How many times a week do you practise kung fu when you are not at your practice?

4. They say: “Money is the root of all evil." We must root out greed in our society.

5. The $\underline{\boldsymbol{c u b}}$ played happily under the protective eye of the lion and lioness.

The sentences above contain words that could easily sow confusion in the minds of ESL learners, especially beginners. Confusion and erroneous usage could result from a juxtaposition of opposites (sentence 1); words with a similar enunciation (sentence 2); verbs and nouns differentiated by spelling (sentence 3); words used in proverbs and idioms (sentence 4); and, words used to denote diminutives or gender. Of course, most texts do not deliberately juxtapose words to confuse ESL students! The argument is that target words need to be differentiated from other words on the basis of:

- opposites,

- $\quad$ similarity in pronunciation,

- minor difference in spelling with resultant change in meaning,

- the manner in which they are used in proverbs and idioms, and

- how they change when referring to diminutive forms or gender.

This differentiation is crucial if ESL learners are to fully grasp not only the meaning of the target word, but the relationship of the target word to other words based on the factors listed above. Multi-dimensional Vocabulary Acquisition (MDVA) is not only about making the meaning of new words explicit to students: it's an attempt to gain a full understanding of a concept with the view to being able to use it in spoken and written communication. Linguists and other language experts often distinguish between receptive and productive vocabulary (Nunan, 2015). Receptive vocabulary refers to those words that a learner can recognize but not use. Productive vocabulary, on the other hand, consists of words that a student can both recognize and use. MDVA is aimed at both kinds of vocabulary. Incidentally, the factors listed above are not an exhaustive array and many more can be added as will be shown. To achieve a multidimensional understanding of key concepts, new terms are looked at in terms of their:

- antonyms and associated words;

- synonyms and associated words;

- rhyming counterparts;

- idiomatic usage;

- gender considerations;

- diminutive implications;

- proverbial usage; and

- likely confusion with other words.

The above list is open-ended and more elements or dimensions can be added. For the purposes of this article only the dimensions listed above will be considered. All the elements or dimensions may not apply to target words. The figure below illustrates a typical Multi-Dimensional Vocabulary ( "MDV") analysis of a target word:

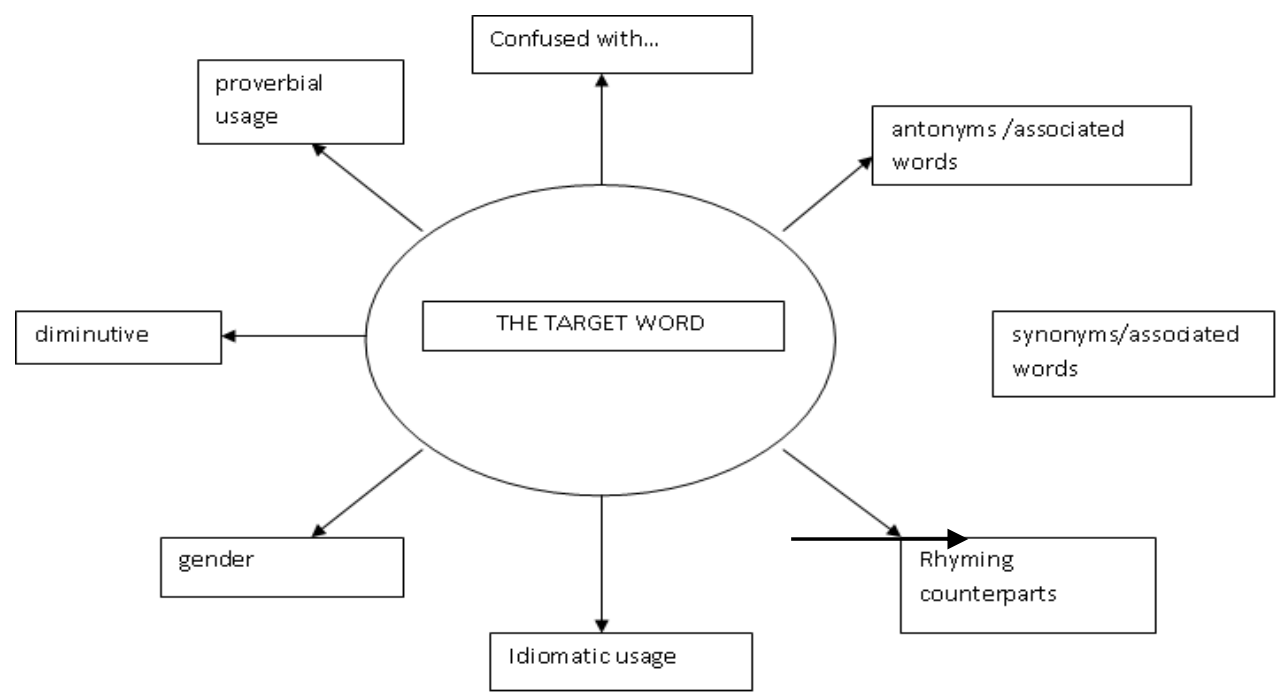

Figure 1. A "MDV" analysis of a target word 


\section{Background}

Before discussing Multi-Dimensional Vocabulary Acquisition further, a background sketch of the author's work environment is necessary. The author teaches English in Saudi Arabia to students whose first language is Arabic. The public schooling system is such that students start learning English when they enter Grade 7. Other students who enrolled at international schools were exposed to English at a much earlier phase, but these are a few cases. In addition, a handful of students supplement their limited English by undertaking short courses or intermittent visits to countries where English is the first or main language of communication, for example, USA, South Africa, England, etc. In any event, students enter College after completing public secondary school education. The College, known as Jeddah Community College, is a satellite campus of King AbdulAziz University (KAU). KAU is a government sponsored institution of higher education. Jeddah Community College has a student population of about 350 males. Prior to registration, students have the option of enrolling for and completing a 3-year associate degree in either Business -, Computer -, or Health Information Technology. Since all programs are taught through the medium of English, all students have to undertake an Intensive English Course in their first year of study. This course supplements whatever English they learnt at secondary school or elsewhere.

\section{What is Multi-Dimensional Vocabulary Acquisition?}

Language specialists sometimes ask the very valid question: "What does it mean to know a word?" At the beginning of the 90s Nation (1990) proposed that eight aspects should be taken into account before a person could claim to have full knowledge of a word, these aspects being: meaning, written form, spoken form, grammatical behavior, collocations, register, associations, and frequency. The author takes a slightly different view and suggests that more aspects or dimensions are involved in fully understanding and using a word. This will become clear shortly. Multi-Dimensional Vocabulary Acquisition (or MDVA) means quite simply approaching words from a variety of perspectives so that the word is thoroughly analyzed giving students access to all "dimensions" of the word. Just as one would have to walk all around an elephant to fully grasp and appreciate all dimensions of the animal, MDVA is a figurative "walk around words". The term may be contradictory, but MDVA is a sort of "structured brainstorming" in which explaining new vocabulary to students would entail looking at some or all of the following elements:

- $\quad$ antonyms and associated words

- synonyms and associated words

- rhyming counterparts

- idiomatic usage

- gender referents

- diminutive referents

- proverbial usage

- $\quad$ words often confused with the target word

A Multi-Dimensional Vocabulary ("MDV") analysis would involve an in-depth consideration of all the above aspects so that words are thoroughly interrogated. Students then have a much broader understanding of the meaning of the word than they did before. A simple example using a few dimensions may help to illustrate the point. If students are required to write a paragraph on the topic "My friend", the word "friend" ( as the target word ) could be subjected to a "MDV" analysis in the following way:

\section{$\underline{\text { Elements or Dimensions }}$}

synonym (companion, mate, confidant)

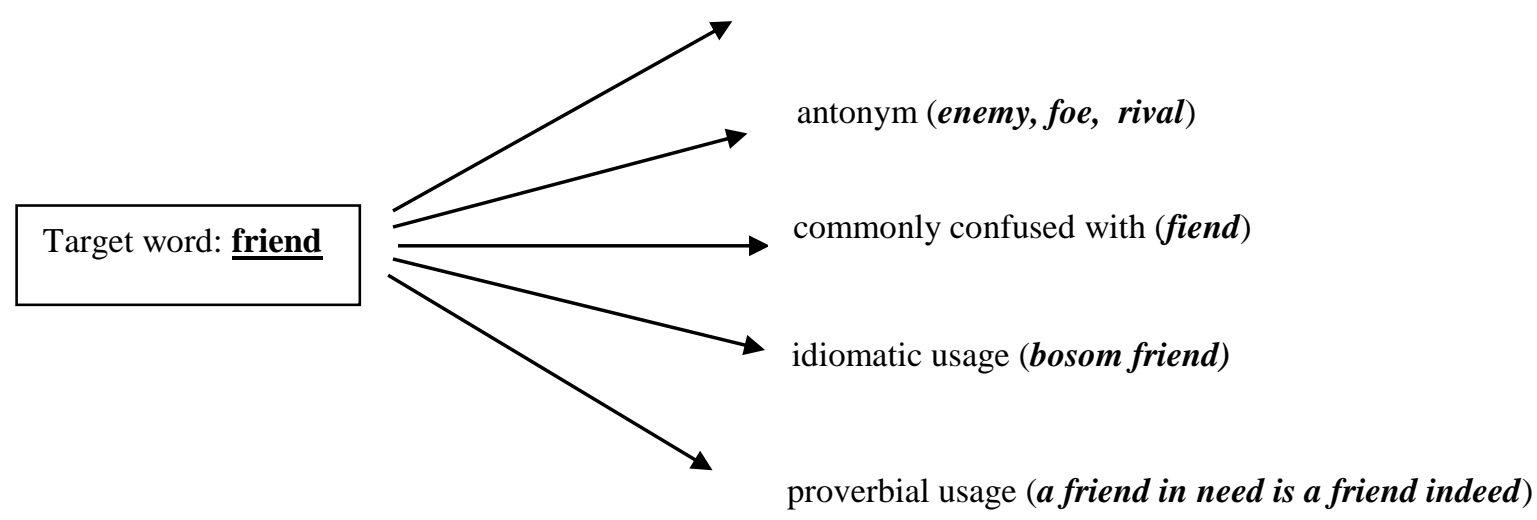

Figure 2. An example of a "MDV" Analysis 
Each of the dimensions in the above analysis will be explained to students. The above elements are in no way an exhaustive list and others may be added, for example, words that rhyme with the target word or its analysed "attachments", denotative or connotative meanings, diminutive form, homophones / homonyms, origins i.e. root word, word combinations, collocations, part of speech, etc. As more words and phrases are generated in the "MDV" analysis, these words / phrases can in turn be subjected to their own "MDV" analysis, and so the process becomes self perpetuating. For example, in the above sketch, one of the antonyms for "friend" is "foe". The word "foe" rhymes with "slow" and "go" so a possible idea that could emerge from this is:

“...My friend is an outdoor kind of person. No, Ali is certainly not slow; he's a guy who's always on the go!"

\section{Why Multi-Dimensional Vocabulary Analysis?}

Why then should we teach vocabulary in a multi-dimensional way? Why expose students to a multiplicity of meanings? Won't this just confuse them? Just as a biologist would most probably say that amino acids are the basic building blocks of life, a linguist might argue that words are the basic building blocks of language. Nunan (2015: 105) states quite categorically that: "Words matter! They are fundamental to successful language acquisition." By realizing that words can have more than one meaning (depending on the context used), second language students can broaden their usage of these words consequently expanding their usage of the language. Becoming aware of more contexts for words leads to more opportunities for explaining the language and thus increasing one's use of it. Another reason is that it aids understanding when the non-native speaker is in an environment that is dominated by native speakers e.g. when visiting, studying or working in a country where English is the first or predominant language.

Vocabulary knowledge is certainly a multifaceted phenomenon (Laufer \& Nation, 2012). Researchers often make a distinction between breadth and depth of vocabulary knowledge. Breadth of knowledge encompasses the number of words learners know (Nation, 2001; Nassaji, 2004). Depth of vocabulary knowledge, on the other hand, is more qualitative in nature (Read, 2000; Nassaji, 2004). Subjecting words to a "MDV" analysis means that learners are achieving both breadth and depth of vocabulary knowledge. It is crucial to realize that as each element of the analysis is completed, the student is generating more ideas for his / her paragraph or essay. In addition, the analyses can be carried out in myriad combinations and permutations and in any order. Some elements may be more readily connected or linked to the target word than others. For example, the word "book" may not lend itself readily to the antonym element of the analysis. The ultimate benefit of this kind of analyses is that students are constantly adding to their repertoire of new vocabulary, thus increasing the likelihood of writing better, more original and interesting paragraphs, compositions, letters, dialogues, reports, etc.

\section{Methodology}

The overarching research design used in this study was qualitative in nature. The research method favoured by the author was Action Research. Action Research is a form of systematic inquiry designed to bring about improvements in one's own practice. Why would anyone want to carry out action research? The answer is to bring about change in specific contexts. Denscombe (2010) asserts that the idea behind Action Research is to solve a specific problem and to generate guidelines for best practice. When educational practitioners think about their work, they ask themselves the following questions:

$>$ What am I doing?

$>$ What do I have to improve?

$>$ How do I improve it?

When practitioners are engaged in this kind of inquiry and then take active measures to address these questions, these people are involving themselves in Action Research. These teachers are investigating and evaluating their own practices.

Some of the characteristics of Action Research are the following: it is cyclic, participative, qualitative, and reflective (Dick, 2000). The research moves along a series of cycles with the reflection at the end of each cycle informing the planning of the next cycle. Kemmis and McTaggart (1988) refer to this as the "action research spiral". The model they propose is the following:

$$
\text { plan } \rightarrow \text { act } \rightarrow \text { observe } \rightarrow \text { reflect (and then } \rightarrow \text { plan } \rightarrow \text { act } \rightarrow \text { observe etc.) }
$$

Short, multiple cycles ensures that a greater amount of rigour will be attained. Each successive cycle is seen as an extension of the initial inquiry.

Action research can be carried out by a group of people. In the case of schools it might mean a group of teachers and the principal investigating an issue jointly. This is known as collaborative action research. On the other hand, individual action research can be conducted by a single teacher or staff member. As Nunan (2003:18) argues: "While collaboration is highly desirable, I do not believe that it should be seen as a defining characteristic of action research." This study is an example of individual action research initiated by the author as a single member of the teaching staff. As such, it is a study that embodies narration, description and reflection. 


\section{Implications for Writing}

In this section the practical benefits of MDVA will be examined. The first exercise considers 2 paragraphs, pre- and post MDVA. Both paragraphs deal with the target word "friend". The first paragraph below is a student's effort on the topic "My friend".

\section{Exercise 1}

\section{PARAGRAPH 1}

\section{My friend}

"My friend's name is Ali. He is 20 years old. He lives with his family.

Ali is a Muslim. He lives in Riyadh. He does not have a job but he is

studying at an engineering college. He is getting married next year.

He wants to become a pilot in the future. I like my friend."

(corrected, adapted, and reproduced with permission)

In terms of lexical content the paragraph is quite bland. The normal, conventional words are used. There is no "depth" of vocabulary usage in the sense of using alternatives or experimenting with other words or expressions. There is a strong likelihood that the student has a restricted vocabulary.

Due to time constraints, the author was unable to undertake a "MDV" analysis of the word "friend" with students. However, we can hypothesize that a "MDV" analysis similar to the one shown in Fig. 2 above could have prompted the student to have produced a paragraph such as the following:

\section{PARAGRAPH 2}

\section{My friend}

My friend's name is Ali. He is 20 years old. He lives with his family. Ali and I are bosom friends. If I had to choose a travelling companion, I would choose Ali. If I had to pick a room- or flatmate, I would pick Ali. If I had a secret I would only tell it to Ali because he is my closest confidant. Ali does not have a job, but he is studying at an engineering college. He is planning to get married next year. He hopes to be a pilot some day. No matter how serious my troubles are, Ali is always there to help. They say: "A friend in need is a friend indeed". This is very true of my friend. I may have many enemies, but if I have one friend like Ali it is enough.

In this second paragraph, the author has used most of the elements in the "MDV" analysis for the target word "friend" ( see Fig. 2 above ). These elements have been highlighted in the paragraph. Paragraph 2 is clearly more varied and richer in vocabulary. It also makes for more interesting reading.

The second exercise again examines a student's effort, but this time pre- and post "MDV" analysis. The process is based on Action Research "spiral of cycles" and has been extended to include a workshop with teaching staff.

\section{Cycle 1: The pre-MDVA stage.}

The author asked students to write a paragraph on the topic: "My House" after basic vocabulary associated with the topic was discussed. As expected, students wrote a physical description of their houses. Typical paragraphs like the following were handed in:

\section{My House}

"My house has four bedrooms. My house has two bathrooms, one kitchen. My house has a garage. My house is very big. My house is quite. My house is modern. My house is safe. My house is very comfortable."

$$
\text { (partly corrected and reproduced with permission) }
$$

\section{Cycle 2: The MDVA stage}

The author then undertook a "MDV" analysis of the word: "house". As students' level of English was low, the author concentrated only on the following dimensions: synonyms / associated words, idiomatic usage and rhyming counterparts. This is represented in the following diagram: 
synonyms/ associated words:

home, flat, dwelling, mansion, palace, apartment, villa, condominium, etc.

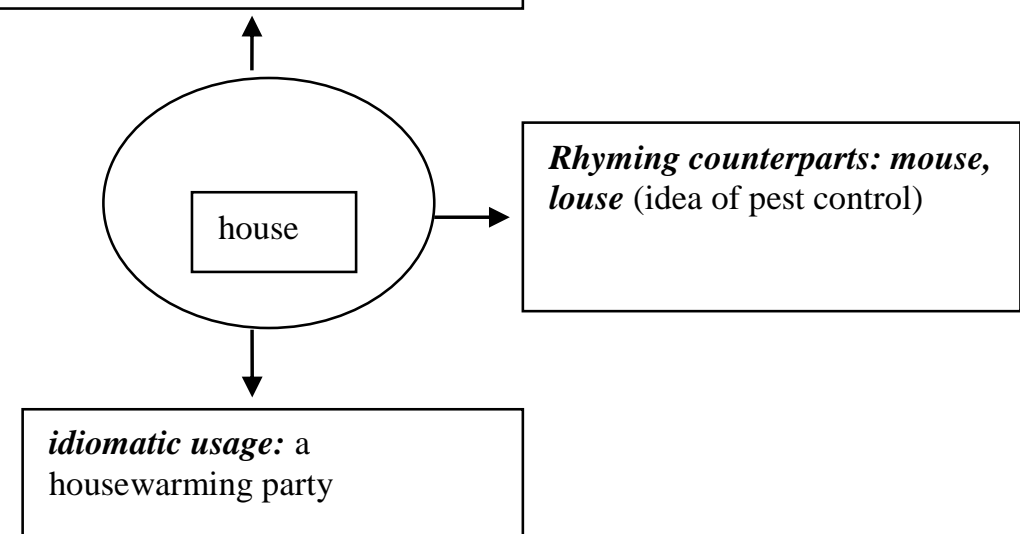

Figure 3. A "MDV" analysis of the word: "house"

On reflection, this was too much information for students to process. They struggled to make the mental link between all these ideas and their own house. No written efforts from students were forthcoming.

\section{Cycle 3: Re-teaching MDVA}

The author then had to re-teach MDVA but with this idea in mind: reduce the amount of information that students have to work with. To reduce information, the author focused on only synonyms and associated words linked to "house", e.g. palace, dwelling, mansion, hut, cave, villa, apartment, flat, condominium, etc. Students were required to consider these words ONLY and reflect on them IN RELATION TO THEIR HOUSE. The idea was to get students thinking in novel ways about a topic that is very conventional. The rule was that these link words associated with "house" (or most of them) should appear in their second paragraph. The following effort from one student is given below:

\section{$\underline{\text { The Cave }}$}

"The cave is one of the places where people have lived since many years ago. These caves have been known as homes and houses that protected people from danger. In these caves there is no air conditioning. It is not safe and is full of holes. There are no bathrooms and kitchens. In addition, there is a lack of comfort which is present today. There are no bedrooms or a dining room. It is so narrow and there is no electricity and water supply. Today the situation has changed and we have comfortable homes. They provide us with safety and comfort."

\section{(partly corrected and reproduced with permission)}

The paragraph has obvious grammatical errors and shortcomings in expression. A purely CONTENT-BASED appraisal of the paragraph shows that the student used just two words from the synonym / associated words dimension, i.e. "cave" and "homes"(already highlighted). Despite this, he did make a comparison of past and present dwellings. It seems as if the idea of the cave triggered off this comparative line of thinking. Although not mentioning it explicitly, the fact that he uses words such as "air-conditioning", "bathrooms", "kitchens", "bedrooms", "electricity", "water supply", suggests strongly that he is differentiating the comforts of a present-day house (possibly his own) and the discomforts of living in a cave. This represents a definite shift in thinking from mere physical description to a comparison of past and present.

\section{Cycle 4 : Workshop with Staff}

As a follow-up to cycles 1, 2 and 3 where only students were involved, the author decided to broach MDVA with his colleagues via a seminar / workshop presentation. After explaining MDVA, the author used the word "stranger" as an example of a target word. The following dimensions of "stranger" were expounded on:

- $\quad$ antonyms and associated words ( friend, acquaintance, mate, etc. )

- $\quad$ synonyms and associated words ( someone unknown, unfamiliar )

- rhyming counterparts ( danger, ranger, )

- idiomatic usage ( "lone ranger", "don’t become a stranger")

- gender ( applicable to male and female )

- diminutive ( not applicable )

- $\quad$ proverbial usage ( not applicable )

- $\quad$ words likely to be confused with the target word ( strangler) 
A diagrammatic sketch of the analysis is presented below.

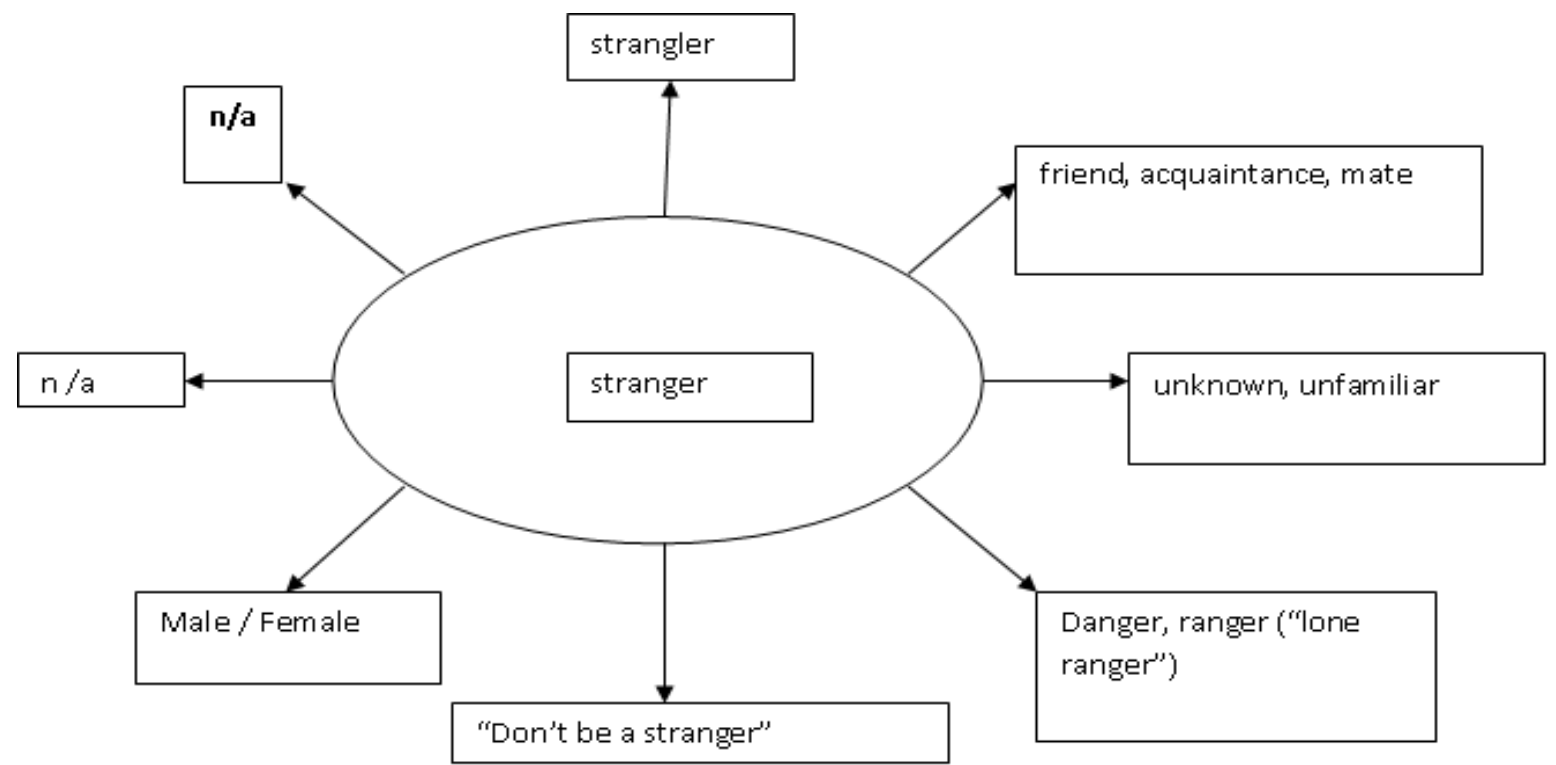

Figure 4. A "MDV" analysis of the word: "stranger"

The author then extracted components from the analysis in Fig. 4 and used them in the following anecdote entitled : "The stranger" :

\section{A short story: The stranger}

When the new semester started I was surprised to find that I had a new roommate at College. I never saw this guy before. He was completely unknown to me. Anyway, he introduced himself as Wayne. Wayne said that he wanted to make many new friends on campus. However, I noticed that he was always alone. I'm not sure whether the other students avoided him, or he deliberately avoided meeting other students. He seemed to be such a "lone ranger". About a month later, I came to our room to find the police talking to Wayne. I overheard them accusing him of being a strangler: he was supposed to have killed 3 people in another city. As they handcuffed him and took him away, he turned to look at me, smiled, and said: " Please visit me in prison. Don't become a stranger..."

The extracted components have been highlighted.

Participants were then asked to form 3 groups, each group consisting of 5/6 members. A member of each group had to pick a folded slip of paper from a box containing several slips. Groups were required to perform 2 tasks:

1. Do a "MDV" analysis of the word written on their slip of paper; and

2. Use some or all the words from their analysis to write a short poem, paragraph, advertisement, dialogue, e-mail message, etc.

The words selected were as follows:

Group 1 : "brain"

Group 2 :"mountain"

Group 3 :"mistake"

Groups were given approximately 5-10 minutes to complete their "MDV" analysis and practical application. The effort of Group 1 is presented below: 


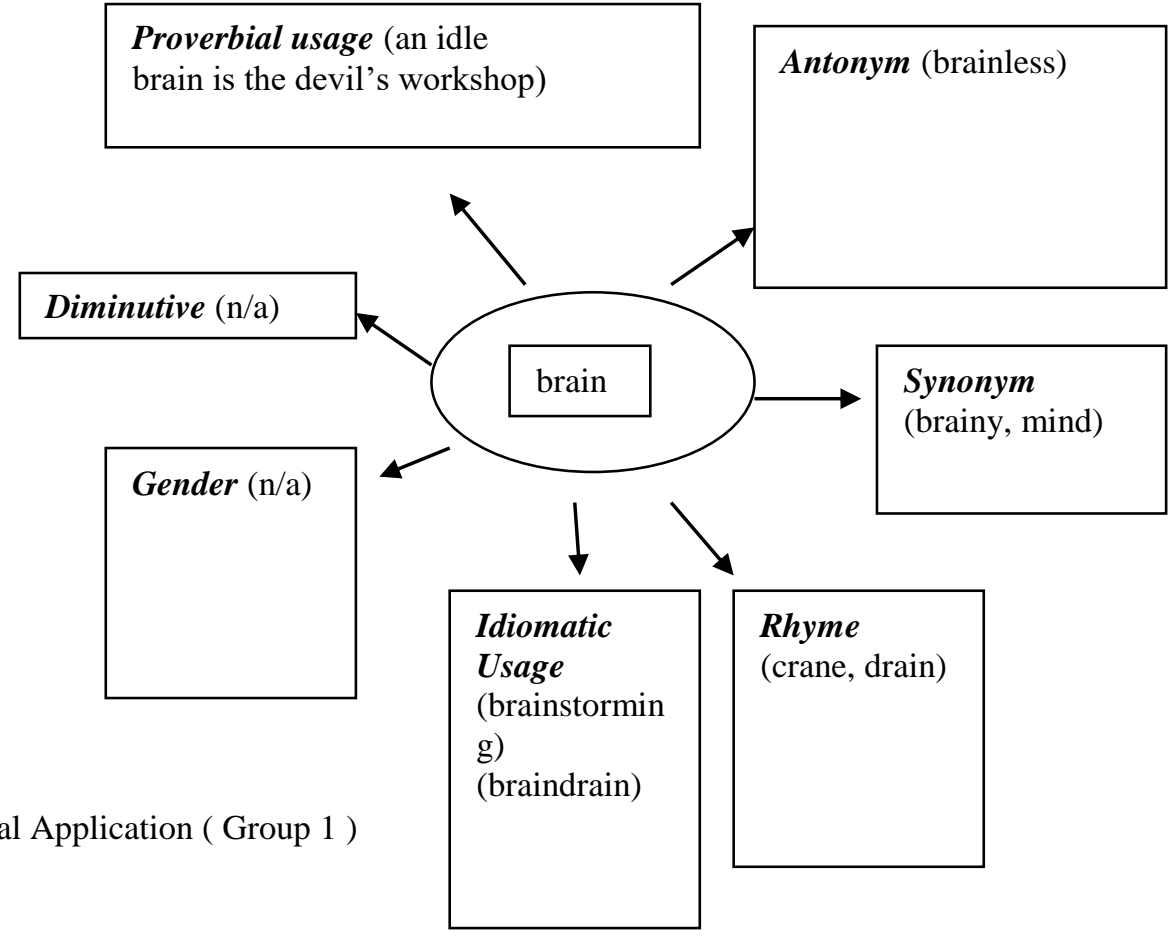

Figure 5. A "MDV" analysis of the word: "brain" (Group 1)

"The brainstorming session at JCC was wonderful and mind blowing. Even the brainless students benefited from it. As they say, an idle brain is the devil's workshop. Not so at JCC: our minds were fully occupied."

\section{(slightly adapted)}

The group used the following elements ( already highlighted ) from their "MDV" analysis:

- idiomatic usage ("brainstorming")

- $\operatorname{synonym}($ ( $\mathrm{mind} / \mathrm{s}$ ")

- antonym (“brainless")

- proverbial usage ( "an idle brain is the devil's workshop")

\section{Findings and Critical Reflection}

The steps in the action research process revealed that MDVA has the potential to improve the quality of students' writing. From a purely content and semantically based perspective, exposure to words/expressions allied to the target word resulted in a shift in thinking thus resulting in a richer piece of writing. This was evidenced in the student's paragraph where he compared a cave to more modern day places of residence. The workshop with staff also showed that toying with words/phrases related to the target word can produce an interesting piece of prose, one that is far from conventional, run-of-the-mill subject matter.

Vocabulary has been taught using a variety of strategies and sources. Chung (2012) mentions a few: teaching new words via reading, small group discussions, sentences that make up a story, context clues, morphological analysis, etc. This study takes a slightly different stance in the sense that the target word becomes the source and the opportunity for teaching new words.

The debate between teaching vocabulary in context versus out of context is well documented. Recent research into this area seems to suggest that it may be better to teach vocabulary to young learners from word lists (the decontextualized approach), and then move to a more context-based method at a later stage of language development (Nation \& Newton, 1997). The present study has utilized elements of both schools of thought. While the initial target word may be from a word list or the unit of study, the resulting piece of prose from the MDV analysis is a richly contextualized production.

English is a lexically rich language. New words are entering the language every day. Nunan (2013) provides a fascinating historical account of the numerical increase of words in the English language; from approximately 100000 over a thousand years ago to more than 600000 in present times! This kind of statistic lends urgency to the need to keep pace, not only in recognizing words, but gaining a comprehensive knowledge of them and their use.

MDVA is not merely teaching the meaning of new or unfamiliar terms. It is an attempt to gain a comprehensive understanding of a concept, and then be able to apply this understanding in written and spoken communication. Nation (2005) makes a distinction between high frequency- and low frequency words. High frequency words are those that are used in daily conversation and which the ESL student can readily use in written and spoken formats. Words of low 
frequency are those associated more with academic texts and courses. They are not part of everyday English usage. They are words belonging to a special register, for example, modify, synthesis, and fusion. As such, these words might prove more challenging for the teacher in his / her Vocabulary lesson. Students are most likely to find these words difficult to understand and retain. This is where MDVA can and should make a difference.

MDVA is an approach that is flexible in the sense that it can be adapted to students' level of English proficiency. The teacher can start with one or two dimensions (possibly antonyms or synonyms) and gradually increase the number of dimensions according to students' abilities. It is crucial that teachers do not lose sight of the practical application of MDVA either in spoken or written form. Students must be able to demonstrate that they have a thorough grasp of the concept by using it with ease in their written and spoken communication. Moreover, reading comprehension is facilitated when students encounter words in texts that have already been elucidated via MDVA in class.

The dimensions themselves in MDVA are subject to expansion depending on the target word under scrutiny. This paper has listed 8 dimensions. However, other dimensions that could be added are: homophones, homonyms, acronyms, popular abbreviations, denotations, connotations, collocations, word combinations, etc. These dimensions can be used in a myriad number of combinations and permutations depending on the ability level of students.

MDVA has many advantages, some of which are listed below:

$\checkmark$ In discussing the target word, the teacher is exposing the students to the meaning of many other words via the various dimensions.

$\checkmark$ Innovative creative thinking is fostered because students are encouraged to make mental connections not only between the target word and words in other dimensions, but also across diverse dimensions.

$\checkmark \quad$ The approach can be adapted to different ability levels.

$\checkmark$ MDVA lends itself readily to practical application in written or spoken form.

$\checkmark$ MDVA aids oral and reading comprehension.

$\checkmark$ As students become more aware of the different contexts in which new words can be used, their confidence in using the language increases.

$\checkmark$ Students are not likely to feel inadequate or embarrassed when surrounded by native

English speakers.

$\checkmark$ The "MDV" analysis lends itself to many different combinations and permutations.

$\checkmark$ A "MDV" analysis can aid in teaching and understanding the meaning of low frequency words.

$\checkmark$ "MDV" analysis increases breadth and depth of vocabulary knowledge.

$\checkmark$ "MDV" scrutiny extends receptive and productive vocabulary.

It is important to remember that becoming familiar with words is a recursive process and does not just happen instantly (Gass, 2013). Learning new vocabulary is an ongoing process that demands time, continual effort and practice. Nakata (2006:19) states that vocabulary acquisition requires continual repetition for effective learning to take place. In addition, the time interval between repetitions is important. As Zimmerman (2014: 292) puts it: "It is not only the number of times that one encounters a word that is important to learning, but also the spacing between the repetitions."

Language facilitators and instructors need to foster a culture of word-consciousness in learners. According to Scott and Scott (2010:1) "Word consciousness is an interest in and awareness of words as building blocks of communication (and) the ability to reflect on, and manipulate words as units of language."

\section{Conclusion}

MDVA is a novel approach to teaching new words and concepts to English second language learners. The teacher is not required to undertake a "MDV" analysis of every word taught in the ESL class. Teachers should decide which are the key terms and concepts they want to emphasize so that students can retain them in their long-term memory. MDVA should then be applied to such key terms and concepts. Nation (2003: 136) contends that: "The most useful vocabulary that every English language learner needs ... is the most frequent 1000 word families in English." The author has highlighted some of the main tenets of MDVA, and then used Action Research "spiral of cycles" to demonstrate their practical application to the classroom.

Learning new vocabulary is not simply a matter of asking students to open a dictionary or their mobile apps. In explaining new terminology, dictionaries sometimes use words that themselves need clarification. This can become a frustrating, vicious cycle for the ESL learner. It is hoped that frequent use of MDVA will help to make vocabulary enrichment more exploratory, interesting, enlightening, and of practical value to our students.

\section{References}

Chung, S.F. (2012) Research-Based Vocabulary Instruction for English Language Learners. The Reading Matrix, 12(2), 105-120.

Daller, H., Van Hout, R. \& Treffers-Daller, J. (2003) Lexical Richness in the Spontaneous Speech of Bilinguals. Applied Linguistics, 24(2), 197-222. 
Denscombe, M. (2010) Good Research Guide: For small - scale social research projects (4 $4^{\text {th }}$ ed.). Open University Press. Berkshire, GBR.

Dick, B. (2000) A beginner's guide to action research [Online]. Retrieved from http://www.uq.net.au/action_research/arp/guide.html

Gass, S.M. (2013) Second Language Acquisition. $4^{\text {th }}$ Edition. New York: Routledge.

Gass, S. M., \& Selinker, L. (2001) Second Language Acquisition ( $2^{\text {nd }}$ d. $)$. New Jersey: Lawrence Erlbaum Associates.

Harrington, M. \& Carey, M. (2009) The on-line Yes/No test as a placement tool. System, 37(4), 614-626.

Hilton, H. (2008) The link between vocabulary knowledge and spoken L2 fluency. Language Learning Journal, 36(2), 153-166.

Ishii, T. \& Schmitt, N. (2009) Developing an Integrated DiagnosticTest of Vocabulary Size and Depth. RELC Journal, $40(1), 5-22$.

Kemmis, S. \& McTaggart, R. eds. (1988) The action research planner, $3^{\text {rd }}$ ed. Victoria: Deakin Univ.

Laufer, B. \& Nation, P. (2012) "Vocabulary." In S.M. Gass \& A. Mackey (Eds.), The Routledge handbook of second language acquisition (pp. 163-176). New York: Routledge.

Nakata, T. (2006) Implementing optimal spaced learning for English vocabulary learning: Towards improvement of the low-first method derived from the re-activation theory. The JALT CALL Journal, 2(2), 3-18.

Nassaji, H. (2004) The relationship between depth of vocabulary knowledge and L2 learners' lexical inferencing strategy use and success. The Canadian Modern Language Review, 61, 107-134.

Nation, P. (1990) Teaching and Learning Vocabulary. Boston: Heinle \& Heinle.

Nation, P. (2001) Learning vocabulary in another language. Cambridge: Cambridge Univ Press.

Nation, P. (2003) Vocabulary. In D. Nunan (ed.) Practical English Language Teaching.New York: McGraw-Hill.

Nation, P. (2005) Teaching vocabulary.Asian EFL Journal, 7(3), 47-54.

Nation, P. \& Newton, J. (1997) “Teaching Vocabulary.” In J. Coady and T. Huckin (Eds.), Second Language Vocabulary Acquisition (pp. 238-54). Cambridge: Cambridge Univ. Press.

Nunan, D. (2003) Research Methods in Language Learning. Cambridge: Cambridge Univ. Press.

Nunan, D. (2013) What Is This Thing Called Language?2 ${ }^{\text {nd }}$ Edition. London: Palgrave Macmillan.

Nunan, D. (2015) Teaching English To Speakers of Other Languages. New York: Routledge.

Pulido, D. \& Hambrick, D.Z. (2008) The virtuous circle: Modeling individual differences in L2 reading and vocabulary development. Reading in a Foreign Language, 20(2), 164-190.

Qian, D.D. \& Schedl, M. (2004) Evaluation of an in-depth vocabulary knowledge measure for assessing reading performance. Language Testing, 21(1), 28-52.

Read, J. (2000) Assessing vocabulary. Cambridge: Cambridge Univ Press.

Read, J. (2007) Second language vocabulary assessment: current practices and new directions. International Journal of English Studies, 7(2), 105-125.

Scott, J. A. \& Scott, D. (2010) Developing word consciousness: Adaptable vocabulary strategies that students (especially English learners) and teachers like and use. Presentation at IRA World Conference, Auckland, New Zealand.

Staehr, L.S. (2009) Vocabulary Knowledge and Advanced Listening Comprehension in English as a Foreign Language. Studies in Second Language Acquisition, 31(4), 577-607.

Webb, S. (2008) Receptive and productive vocabulary sizes of L2 learners.Studies in Second language acquisition, 30(1), 79-95.

Yu, G. (2010) Lexical diversity in writing and speaking task performances.Applied Linguistics, 31(2), 236-259.

Zimmerman, K.J. (2004) The role of vocabulary size in assessing second language proficiency, MA Thesis, Brigham Young Univ.

Zimmerman, C. (2014) Teaching and learning vocabulary for second language learners. In M. Celce-Murcia, D. Brinton, and M.A. Snow (eds.) Teaching English as a Second or Foreign Language. Boston: National Geographic Learning/Cengage.

Zareva, A., Schwanenflugel, P. \&Nikolova, Y. (2005) Relationship between lexical competence and language proficiency: Variable sensitivity. Studies in Second Language Acquisition, 27(4), 567-595. 